\title{
Molecular Characterization of Scarlet and Gboma Eggplants Based on Single Nucleotide Polymorphisms
}

\author{
Dionís BORRÀS, Mariola PLAZAS, Isabel ANDÚJAR, Pietro GRAMAZIO, Francisco \\ Javier HERRAIZ, Jaime PROHENS, and Santiago VILANOVA*
}

Institut de Conservació i Millora de l'Agrodiversitat Valenciana. Universitat Politècnica de València, Spain.

*)corresponding author, e-mail: svilano@upvnet.upv.es

BulletinUASVM Horticulture 72(2) / 2015

Print ISSN 1843-5254, Electronic ISSN 1843-5394

DOI:10.15835/buasvmcn-hort:11408

\begin{abstract}
The common eggplant (Solanum melongena) is one of the most economically important specie for cultivated aubergine . The relationship between eggplant and it the wild relatives has been controversial. The domestication of the cultivated species has resulted in a narrow genetic base, and this difficults further improvements. Here we have characterized 48 accessions belonging to the cultivated scarlet eggplant (S. aethiopicum) and it wild ancestor (S. anguivi), the cultivated gboma eggplant (S. macrocarpon) and its wild ancestor ( $S$. dasyphyllum), including also one accession of cultivated eggplant and one of its wild ancestor ( $S$. incanum) using 39 single nucleotide polymorphism (SNP) markers. A total of 82 alleles were detected with an average of 2.34 alleles/locus. A good differentiation between the three groups corresponding to common, scarlet and gboma eggplants was obtained with a PCoA analysis. These results are of interest for the enhancement of genetic resources of eggplants.
\end{abstract}

Keywords: genetic diversity, high resolution melting, Solanum spp., SNPs, wild relatives.

\section{Introduction}

The relationship between common eggplant (Solanum melongena) and cultivated and wild relatives of genus Solanum has been controversial (Knapp et al., 2013). It is likely that the consumed eggplant today is the result of the domestication of wild species Solanum incanum.

The domestication has ended with a genetic impoverishment and therefore making the eggplant susceptible to many diseases. In this context the wild related species have an interesting role as they are a source of genetic and allelic variation for different important traits. Given the potential for hybridization of eggplant with cultivated scarlet (S. aethiopicum) and gboma (S. macrocarpon) eggplants as well as with their wild relatives $S$. anguivi and $S$. dasyphyllum, the study of the diversity and relationships of these materials is of interest.
Aims

This work is aimed at the detailed molecular characterization of a germplasm collection of scarlet and gboma eggplant and some related species. This will allow us to perform a genetic diversity study and this way to identify potentially interesting accessions for future breeding programs.

\section{Materials and Methods}

Here we have characterized 48 accessions, belonging to $S$. aethiopicum (29), S. anguivi (2), intermediate forms $S$. aethiopicum - S. anguivi (8), $S$. macrocarpon (6), $S$. dasyphyllum (2) and the eggplant close wild relative $S$. incanum (1), using 39 SNPs markers and the High Resolution Melting (HRM) technique. Observed $\left(\mathrm{H}_{\mathrm{o}}\right)$ and expected $\left(\mathrm{H}_{\mathrm{e}}\right)$ heterozygosity and the polymorphic information content (PIC) were calculated. A principal 
Principal Coordinates (PCoA)

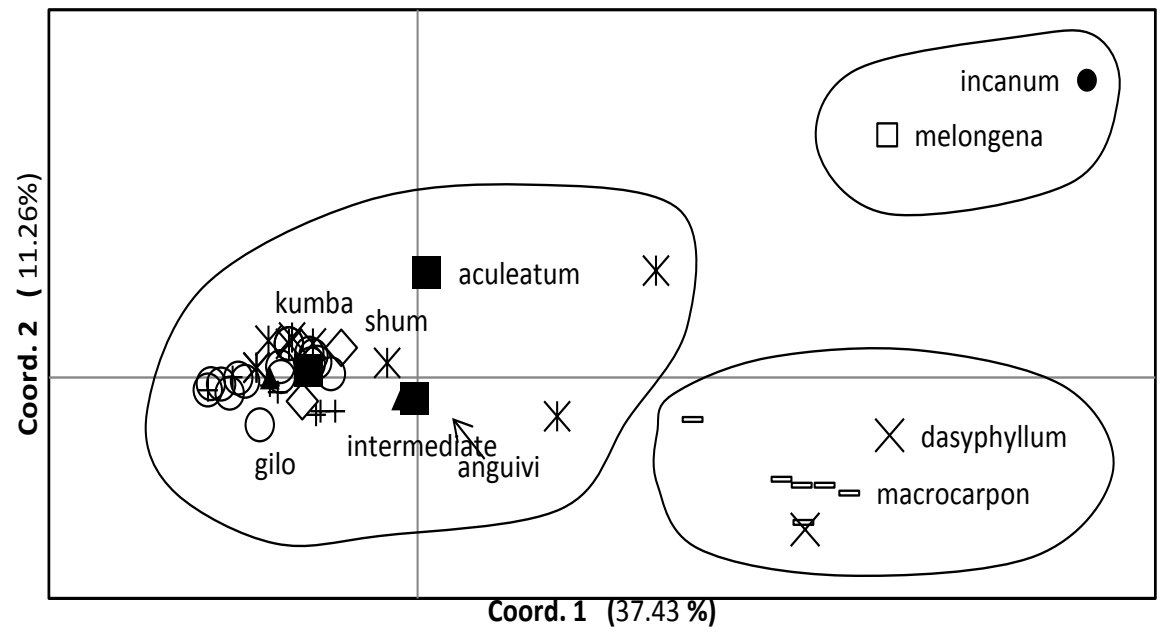

Fig. 1. Genetic similarity based on 49 accessions and 35 SNPs markers represented on the two first principal components of PCoA. The first and the second component explain the 37.43 and $11.26 \%$ of the total variation respectively. The 10 groups are represented with different symbols: S. anguivi $(\mathbf{\Lambda})$, S. dasyphyllum $(\times)$, S macrocarpon $(-), S$. aethiopicum groups Gilo $(\bigcirc)$, Aculeatum $(\square)$, Kumba $(*)$ and shum $(\diamond)$, the intermediate groups between $S$. aethiopicum and $S$. anguivi $(+)$, S. incanum $(\bullet)$ and $S$. melongena $(\square)$.

components analysis (PCoA) was performed with the genetic data.

\section{Results}

Thirty-five outofthe39SNPsgaveamplification of good quality. A total of 82 alleles were detected, with an average of 2.34 alleles/locus. $\mathrm{H}_{\mathrm{e}}$ had an average value of 0.22 , while $\mathrm{H}_{0}$ of 0.02 , revealing a high homozygosis in the materials. The average for PIC was 0.19 with a wide range of variation. The PCoA (Figure 1) were able to distinguish the species as well as to reveal that a wide variation exists within species. The results also confirm that the SNPs selected are good enough to perform this kind of analysis, which in the future will allow us to use them in massive genotyping platforms such as SNPplex.

\section{Conclusion}

The data obtained in this study reveal that, as occurs for morphological traits (Plazas et al., 2014) there is a wide diversity in African scarlet and gboma eggplants. This has important implications for eggplant breeding. Also, SNPs are very valuable for characterization of eggplant relatives, which is of interest for germplasm management, conservation and breeding. The PCoA were able to distinguish the species but were not that good distinguishing the different groups within a specify species. This reveals that a wide variation exist within species. The data here obtained will contribute in the selection and breeding of individuals of potential interest.

\section{REFERENCES}

1. Knapp S, Vorontosova M, Prohens J (2013). Wild relatives of eggplant (Solanum melongena L.: Solanaceae): New understanding of species names in a complex group. PLOS ONE 8:e57039.

2. Plazas M, Andújar I, Vilanova S, Gramazio P, Herraiz FJ, Prohens J (2014). Conventional and phenomics characterization provides insight into the diversity and relationships of hypervariable scarlet (Solanum aethiopicum L.) and gboma (S. macrocarpon L.) eggplant complexes. Frontiers in Plant Science 5:318. 